\title{
Analysis of monotherapy prostate brachytherapy in patients with prostate cancer. Initial PSA and Gleason are important for recurrence?
}

\author{
Pedro Galego ${ }^{1}$, Fernando C. Silva ${ }^{1}$, Luís Campos Pinheiro ${ }^{1}$ \\ ${ }^{1}$ Section of Urology, São José Hospital, CHLC, Lisboa, Portugal
}

\section{ABSTRACT}

Purpose: To evaluate the clinical outcome of a cohort of localized prostate cancer patients treated with 125-I permanent brachytherapy at the São José Hospital - CHLC, Lisbon.

Materials and Methods: A retrospective analysis was carried out on 429 patients with low and intermediate-risk of prostate adenocarcinoma, according to the recommendations of the EORTC, who underwent 125I brachytherapies in intraoperative dosimetry "real-time" system between September 2003 and September 2013.

Results: The mean follow-up was 71.98 months. Biochemical relapse of disease by rising PSA (Phoenix criterion) was observed in 18 patients (4.2\%). Through the application of Kaplan-Meier survival curves in this sample, the rate of survival at 6 years without biochemical relapse was higher than 95\%. By Iog rank test comparing biochemical relapse with initial PSA (15-10 and <10) and Gleason values (7 and <7), there was no statistical difference $(\mathrm{P}=0.830)$ of the initial PSA in the probability of developing biochemical relapse. In relation to Gleason score, it was noted a statistical difference $(\mathrm{P}<0.05)$, demonstrating that patients with Gleason 7 are more likely to develop biochemical relapse.

Conclusions: Brachytherapy as monotherapy is at present an effective choice in the treatment of localized prostate adenocarcinoma. Biochemical relapses are minimal. The initial PSA showed no statistically difference in the rate of relapses, unlike the value Gleason, where it was demonstrated that patients with Gleason 7 have a higher probability of biochemical relapse. Cases with PSA bounce should be controlled before starting a salvage treatment.

\section{ARTICLE INFO}

Key words:

Brachytherapy; Prostate; Patient Outcome Assessment; Disease Management

Int Braz J Urol. 2015; 41: 353-9

Submitted for publication:

December 15, 2013

Accepted after revision:

July 27, 2014

\section{INTRODUCTION}

Currently, active treatment of prostate carcinoma in patients with localized disease and long life expectancy is recommended (1). Clinically localized prostate cancer is typically managed by well established therapies like radical prostatectomy, brachytherapy, and external beam radiation therapy. Permanent brachytherapy (BT) with 125-I seed implant gets PSA control 10 years higher than that reported with external radiotherapy (ERT), and comparable to radical prostatectomy (RPT) (2-7). Brachytherapy was developed to treat prostate cancer 50 years ago and already have a lot of publication in the entire world and there are already publications with 15 years 
of monitoring (8). There is a perception that only large centers obtain satisfactory long-term results. Therefore, we decided to review our experience in 429 patients treated according to the American (9) and European (10) recommendations, with braided seeds according to a transperineal ultrasound-guided radioactive seed implantation, in a "real-time" system; if we had adequate results, the technique could be improved or the indications of the BT should be adjusted further. In Portugal, about 8 centers have implemented this technique, but there aren't published results. So, it was time to start our evaluation in Portugal.

\section{MATERIALS AND METHODS}

In September 2003, we started the treatment of prostate carcinoma with radioactive I-125 seeds. Until September 2013, we performed 429 implants with intraoperative dosimetry "realtime" system by transperineal ultrasound-guided - Mount Sinai School of Medicine (11). This review included consecutive low and intermediate-risk patients, according to the classification of D'Amico (12) modified according to the recommendations of the EORTC (10): low risk with PSA $<10$, Gleason 2-6, stageT1-T2a; intermediate risk with PSA 1020, Gleason score 7, stage T2b-c (T2c was included as intermediate risk according to the EORTC criteria). No high-risk cases (PSA $>20$, Gleason 8-10, T3) or with three intermediate-risk factors were included. Other exclusion criteria were: life expectancy $<5$ years, compromised urinary function (International Prostate Symptoms Score: IPSS > 20), and transurethral resection (TUR) in the last 6 months. All patients signed a specific informed consent.

The mean age was 67.4 years (46-75 years). The median PSA level before BT (Initial PSA) was $6.8 \mathrm{ng} / \mathrm{mL}(2,10-15), 86 \%<10$ and 14\% 10-15. Clinical stage was T1-T2a in $98.1 \%$ and T2b-c in 1.9\%. All patients were diagnosed with adenocarcinoma through ultrasound-guided biopsy. The Gleason score was 6 in 90\% and 7 in 10\%. Lowrisk cases were 74\% and intermediate-risk 26\% (Table-1). In all patients with intermediate-risk was required a negative biopsy of seminal vesicles. Only two patients presented two intermediate-risk
Table 1 - Characteristics of the $\mathbf{4 2 9}$ patients.

\begin{tabular}{ccc}
\hline & Patients & Percentage \\
\hline Age $<$ 55 & 11 & $2.6 \%$ \\
Age 55-59 & 51 & $11.9 \%$ \\
Age 60-64 & 91 & $21.3 \%$ \\
Age 65-69 & 147 & $34.2 \%$ \\
Age 70-75 & 129 & $30 \%$ \\
Clinical stage & & \\
T1a-b & 9 & $2.1 \%$ \\
T1c & 263 & $61.3 \%$ \\
T2a & 149 & $34.7 \%$ \\
T2b & 5 & $1.2 \%$ \\
T2c & $369 \%$ \\
Gleason & $30.7 \%$ \\
G6 & 386 & $10 \%$ \\
G7 & & \\
PSA & & $90 \%$ \\
PSA 10-15 & $33 \%$ \\
\hline
\end{tabular}

factors. Hormonal therapy (HT) was used in 105 patients $(24.5 \%)$, to reduce prostate volume $>60$ cc (LH-RH analogue for three months).

The volumetry was calculated three and four weeks before the implant using transrectal ultrasound. If the volume was greater than $60 \mathrm{cc}$, hormonal treatment was offered and repeated at three months.

All patients (low and intermediate-risk) underwent a brachytherapy as monotherapy by transperineal ultrasound-guided "real-time" system, and the prescribed minimum peripheral dose for prostate was $140 \mathrm{~Gy}$. The main objective was to achieve the following constraints: V100>98\% (prostate volume receiving 100\% dose); D90>140 Gy (dose that 90\% of the prostate receives); V150 urethra $<1 \%$ (volume of the urethra receiving $150 \%$ dose), and rectal V100<5\% (volume of the 
rectum that receives $100 \%$ dose). The number of seeds and the implant location were prepared in the operating room. The median seed activity was $0.508 \mathrm{mCi}(0.399-0.603 \mathrm{mCi})$. The patients were discharged the following day. They were given an appointment a month after the implant for CT definitive dosimetry.

The PSA control was performed every three months the first year, every four the second, every 6 months up to 5 years and annually thereafter. Biochemical relapse (BR) was considered according to the Phoenix criterion: PSA nadir+2ng/ $\mathrm{mL}$ (13). Toxicity was measured with the RTOP/ EORTC scale and urinary function also with IPSS. Sexual function was measured by the scale of the National Cancer Institute. For biochemical control statistical analysis, the Kaplan-Meier test was performed. We applied the Iog rank test by crossing the biochemical relapses with initial PSA values (Group 1) and the values of Gleason (Group 2) to evaluate its statistical significance.

\section{RESULTS}

The mean follow-up was 71.98 months (6 years), maximum 119.73 months and at least 3 months. Eleven patients died of concurrent disease not associated with prostate cancer. Twen-

Figure 1 - Results of the total actuarial biochemical control by Kaplan-Meier test.

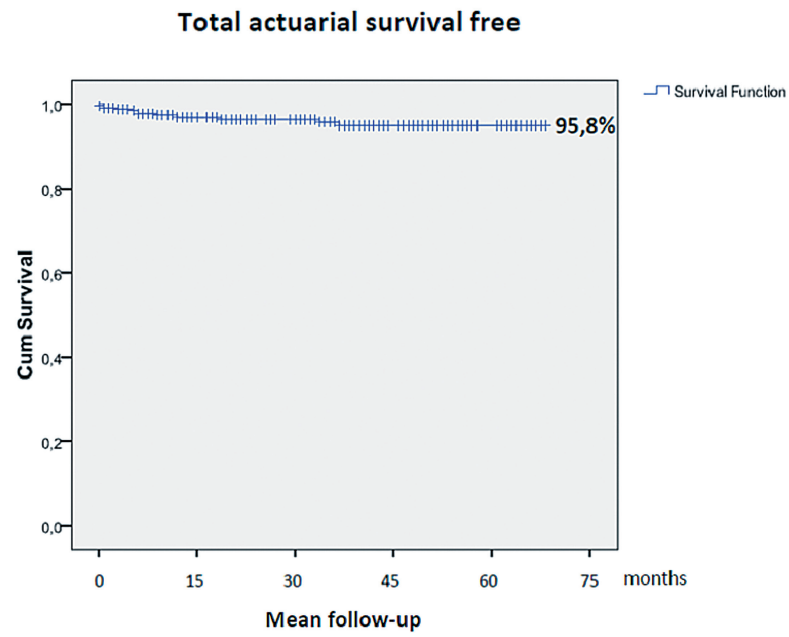

ty-five patients had PSA elevations with risk of biochemical relapse. Seven patients (1.6\%) with theoretical BR remained untreated because the PSA remained at levels below the diagnostic ones and below 10, with negative extension studies and/or negative biopsy, and in them PSA declined spontaneously. Therefore, only 18 patients actually had BR (4.2\%). Sixteen of them had a positive prostate biopsy and were treated with HT (two with cryotherapy). Two cases were not biopsied due to advanced age and starting HT because PSA was $>10 \mathrm{ng} / \mathrm{mL}$. The mean age of the 18 patients with BR was 67.8 years (56-75). All the 18 patients had local recurrences and did not undergo HT previously to BT for prostate downsizing.

The actuarial survival free of BR at 6 years was $95.8 \%$ (Figure-1). In cases of low and intermediate risk it was $95.5 \%$ and $89.2 \%$, respectively. There were no statistical differences according to Initial PSA on the BR - Group 1. Patients with PSA $<10$ had a BR-free survival of 96.2\%, compared to 95.7\% with PSA 10-15 ( $p=0.830)$ (Figure-2). However, when we compared the Gleason score on the BR Group 2, the patients with Gleason 6 had a BR-free survival of $95.6 \%$ compared to $87.5 \%$ with Gleason $7(\mathrm{p}<0.05)$ (Figure-3). Time until BR was between 14 and 104 months (mean 46.8 months). Transient PSA elevation was studied in a subgroup of 120

Figure 2 - Results of crossing the biochemical relapses with Initial PSA values (Group 1) by log rank test.

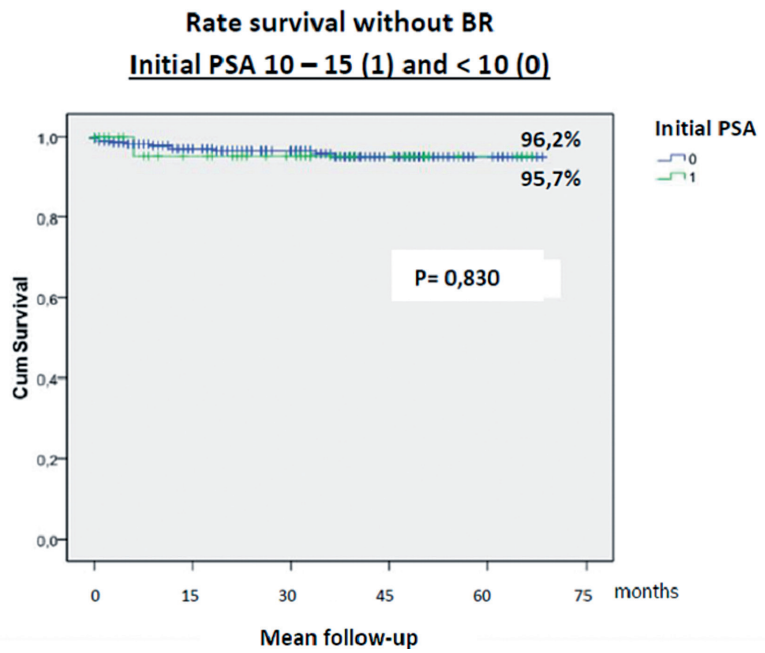


Figure 3 - Results of crossing the biochemical relapses with Gleason score (Group 2) by log rank test.

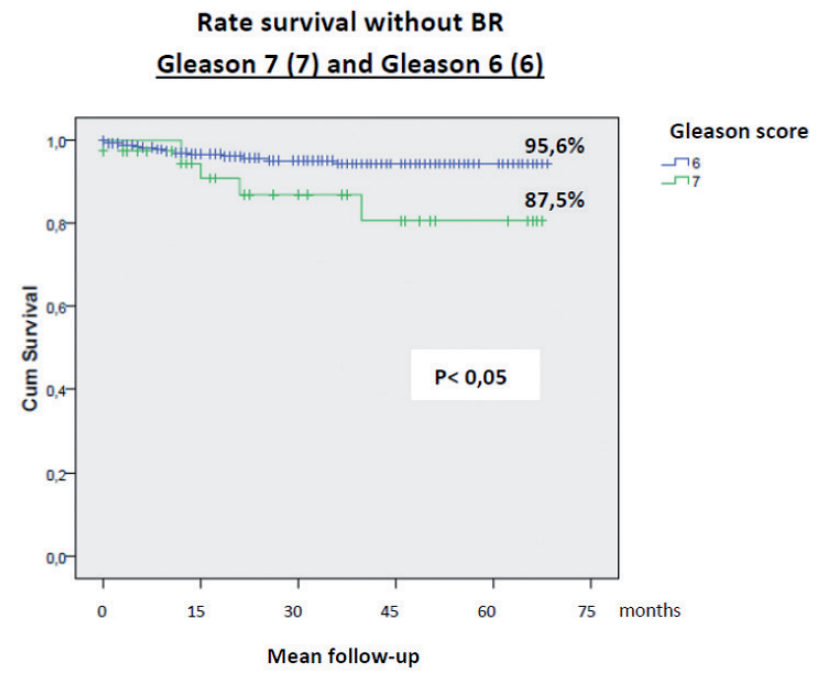

patients in a 6 months follow-up. An increase of $>0.1 \mathrm{ng} / \mathrm{mL}$ was detected in $49 \%$ (28\% without $\mathrm{HT}$, $79 \%$ with HT). When an increase of $>0.4 \mathrm{ng} / \mathrm{mL}$ was considered, the transient elevations was $14 \%$ (8.5\% without HT, 21\% with HT). The median PSA nadir in the group PSA $<10$ was $1.08 \mathrm{ng} / \mathrm{mL}$ and in the group PSA $10-15$ was $1.56 \mathrm{ng} / \mathrm{mL}$. The median PSA nadir in the group Gleason 6 was $1.46 \mathrm{ng} / \mathrm{mL}$ and in the group Gleason 7 was $1.63 \mathrm{ng} / \mathrm{mL}$.

Rectal acute complications are related to the endorectal probe, G2: 0.6\%, G1: 17\%. Rectal late toxicity was minimal with only five cases of rectal bleeding (1.2\%) (G2: 2, G1: 3). Posttreatment rectal fistulas were not found. Hematuria occurred in some cases during the first and second day. No case of long-term incontinence or hematuria has been detected (G0). Mean IPSS before the implant was $8(0-18)$ and mean time for full recovery was 5.5 months (range 0-16 months). We had to probe $6.5 \%$ patients due to acute urinary retention, which resolved within two months. The side effects were of low intensity in 58\% of the patients. Desobstructive TUR$P$ was necessary in 10 patients, average of 27 months (16-39 months) after treatment. 141 patients (33\%) have only mild to moderate urinary complaints (dysuria, urinary frequency) controlled with oral therapy ( $\alpha$-blockers).
Sexual function was determined in the first 260 patients (using International Index of Erectile Function - IIEF) and discarding previous cases of impotence, it was preserved in 60\% of the patients. Analyzing only the cases that did not receive HT, 12\% had prior impotence, and those with some degree of erection, one year after implantation, 76\% of patients had regained the same level of prior sexual activity.

Regarding the CT dosimetric data at one month of the implant, a mean V100 of 93.7\% (81.08-98.98\%) and D90 of 177.68 Gy (140-225 Gy) was obtained. Mean prostate size was 43.9 cc (14-65 cc).

\section{DISCUSSION}

All the patients, of low and intermediate risk, received prostate brachytherapy as monotherapy. Permanent TB in low-risk cases gets biochemical control at 10 years between $87 \%$ and $96 \%$, and in intermediate-risk ones between $63 \%$ and $86 \%$ (14). Our study at 6 years (95.5\% low risk, $89.2 \%$ intermediate) confirms the same results, however, most of the cancers treated in this cohort were probably clinically insignificant cancers.

Many clinical factors have been described that influence the result, PSA level, Gleason, T stage, percentage of positive biopsy cylinders, $(10,14)$ but in our study only the Gleason score was significant.

A quarter of cases in our study received HT (24.5\%), but it did not improve the results. In the series of Mount Sinai School of Medicine (11) and Leeds (15), the HT did not influence the BR significantly. It is queried whether permanent implants are suitable for young men. In our study, of 62 patients $<60$ years, only one suffered a relapse, and all preserved sexual potency. A study by the Mount Sinai School of Medicine confirms that men up to 60 years old achieve an excellent biochemical control at 8 years, comparable to older ones (16).

Transient PSA elevations are another datum to be studied. They are defined as an elevation of the PSA above the initial nadir, which later declines without any treatment. However, different 
definitions of the BR lead to false positives while transient elevations last (17). In our work, 7 of 25 cases with theoretical BR were monitored without treatment and the PSA declined. Mean time to the onset of the PSA elevation is a useful indicator. In our series, the real BR occurred at an average of 46.8 months and the false ones at 24 months. A study in Toronto with 292 patients showed that the median time to the PSA elevation indicative of the BR was 30 months, and concluded that caution is advised in interpreting an early increase in the PSA level in the first 30 months (18). The time to the first PSA elevation is the most valuable factor to distinguish between a transient increase and a $\mathrm{BR}$, considering that transient elevations are more common in young men and that these cases have a better prognosis, as demonstrated in a study of 820 patients: control rate at 5 years in patients with elevation $\geq 0.2$ was $97.7 \%$ vs. $91 \%$ in those who did not have transient PSA elevation (19).

Performing a post-implant dosimetry in patients undergoing permanent prostate BT is essential (20) to know the D90 and V100, which correlate with the result (21). Doses higher or lower than 150 Gy were the only prognostic factor in 558 patients at intermediate risk at Memorial Sloan Kettering Cancer Center (22). With D90 $>140$ Gy control reached 93\% at 10 years. At the Mount Sinai School of Medicine, in 243 patients on monotherapy, a group of optimal dose $(\geq 140$ Gy D90) was distinguished with control at 8 years of $82 \%$ and suboptimal (D90 < $140 \mathrm{~Gy}$ ) of $68 \%$. In low-risk cases, this difference was $94 \%$ vs. $75 \%$ (11). The Leeds experience was similar (23), significant only in low-risk cases (24).

We used the intraoperative dosimetry system that allows the immediate calculation of each seed when inserted into the prostate gland. The dose distribution for the implant is calculated in "real time" in the operating room, and new seeds can be inserted if cold areas are detected. When the implant is finished, the dosimetry reflects the dose distribution in agreement with the position in which the seeds have remained, properly identified with ultrasound images, which makes possible to get a better D90 and V100. Although there are slight differences between the results of intraoperative dosimetry and that performed monthly by $\mathrm{CT}$, the intraoperative implant dosimetric system allows for a good approximation to the real administered dose (25). When it was performed right at the end of the implant, in the operating room and under ultrasound control, the V100 reached 97\% and the D90 177 Gy. Planning based on real-time ultrasound does not accurately reflect dosimetry based on postoperative CT (26), although the prostate edges are better defined by ultrasound than by CT.

In a study of 2,693 patients from 11 institutions treated with permanent BT monotherapy, the only controllable factor with long-term impact was the D90, which reflects the quality of the implant (27). The impact of these changes will lead to better results, obtained through a closer integration of planning processes with the actual implant and the way to place the seeds (28).

In conclusion, the result of the monotherapy treatment with 125-I seeds in patients with low and intermediate-risk carcinoma is very good and with few complications. The hormone treatment did not affect the results. The PSA elevations must be controlled and, thus, a premature salvage therapy avoided. Biochemical relapses are minimal. In our sample, the initial PSA showed no statistically differences in the rate of relapses, unlike the value Gleason, where it was demonstrated that patients with Gleason 7 have a higher probability of biochemical relapse.

\section{CONFLICT OF INTEREST}

None declared.

\section{REFERENCES}

1. Kirollos M. Re: Axel Heidenreich, Gunnar Aus, Michel Bolla, et al. EAU guidelines on cancer. Eur Urol 2008;53:68-80.Eur Urol. 2008;54:693-5; author reply 695-7.

2. Ragde H, Elgamal AA, Snow PB, Brandt J, Bartolucci AA, Nadir BS, et al. Ten-year disease free survival after transperineal sonography-guided iodine-125 brachytherapy with or without 45-gray external beam irradiation in the treatment of patients with clinically localized, low to high Gleason grade prostate carcinoma. Cancer. 1998:83:989-1001. 
3. Ragde H, Korb LJ, Elgamal AA, Grado GL, Nadir BS. Modern prostate brachytherapy. Prostate specific antigen results in 219 patients with up to 12 years of observed follow-up. Cancer. 2000;89:135-41.

4. Grimm PD, Blasko JC, Sylvester JE, Meier RM, Cavanagh W. 10-year biochemical (prostate-specific antigen) control of prostate cancer with (125)I brachytherapy. Int J Radiat Oncol Biol Phys. 2001;51:31-40.

5. Stokes SH. Comparison of biochemical disease-free survival of patients with localized carcinoma of the prostate undergoing radical prostatectomy, transperineal ultrasound-guided radioactive seed implantation, or definitive external beam irradiation. Int J Radiat Oncol Biol Phys. 2000;47:129-36.

6. Henry AM, Al-Qaisieh B, Gould K, Bownes P, Smith J, Carey $B$, et al. Outcomes following iodine-125 monotherapy for localized prostate cancer: the results of leeds 10-year singlecenter brachytherapy experience. Int $J$ Radiat Oncol Biol Phys. 2010;76:50-6.

7. Hinnen KA, Battermann JJ, van Roermund JG, Moerland MA, Jürgenliemk-Schulz IM, Frank SJ, van Vulpen M. Long-term biochemical and survival outcome of 921 patients treated with I-125 permanent prostate brachytherapy. Int J Radiat Oncol Biol Phys. 2010;76:1433-8.

8. Sylvester JE, Grimm PD, Blasko JC, Millar J, Orio PF 3rd, Skoglund S, Galbreath RW, Merrick G. 15-Year biochemical relapse free survival in clinical Stage T1-T3 prostate cancer following combined external beam radiotherapy and brachytherapy; Seattle experience. Int J Radiat Oncol Biol Phys. 2007;67:57-64.

9. Nag S, Beyer D, Friedland J, Grimm P, Nath R. American Brachytherapy Society (ABS) recommendations for transperineal permanent brachytherapy of prostate cancer. Int J Radiat Oncol Biol Phys. 1999;44:789-99.

10. Ash D, Flynn A, Battermann J, de Reijke T, Lavagnini P, Blank $L$, et al. ESTRO/EAU/EORTC recommendations on permanent seed implantation for localized prostate cancer. Radiother Oncol. 2000;57:315-21.

11. Kollmeier MA, Stock RG, Stone N. Biochemical outcomes after prostate brachytherapy with 5-year minimal follow-up: importance of patient selection and implant quality. Int $\mathrm{J}$ Radiat Oncol Biol Phys. 2003;57:645-53.

12. D'Amico AV, Whittington R, Malkowicz SB, Cote K, Loffredo M, Schultz D, et al. Biochemical outcome after radical prostatectomy or external beam radiation therapy for patients with clinically localized prostate carcinoma in the prostate specific antigen era. Cancer. 2002;95:281-6.

13. Roach M 3rd, Hanks G, Thames H Jr, Schellhammer P, Shipley WU, Sokol GH, et al. Defining biochemical failure following radiotherapy with or without hormonal therapy in men with clinically localized prostate cancer: recommendations of the RTOG-ASTRO Phoenix Consensus Conference. Int J Radiat Oncol Biol Phys. 2006;65:965-74.
14. Budía Alba A, Bosquet Sanz M, Tormo Micó A, Boronat Tormo F, Alapont Alacreu JM, Francés A, et AL. Indications, results and techniques of permanent prostate brachytherapy for localized prostate cancer. Actas Urol Esp. 2007;31:452-68.

15. Ash D, Al-Qaisieh B, Bottomley D, Carey B, Joseph J. The impact of hormone therapy on post-implant dosimetry and outcome following lodine-125 implant monotherapy for localised prostate cancer. Radiother Oncol. 2005;75:303-6.

16. Burri RJ, Ho AY, Forsythe K, Cesaretti JA, Stone NN, Stock RG. Young men have equivalent biochemical outcomes compared with older men after treatment with brachytherapy for prostate cancer. Int J Radiat Oncol Biol Phys. 2010;77:1315-21.

17. Mitchell DM, Swindell R, Elliott T, Wylie JP, Taylor CM, Logue JP. Analysis of prostate-specific antigen bounce after I(125) permanent seed implant for localised prostate cancer. Radiother Oncol. 2008;88:102-7.

18. Crook J, Gillan C, Yeung I, Austen L, McLean M, Lockwood G. PSA kinetics and PSA bounce following permanent seed prostate brachytherapy. Int J Radiat Oncol Biol Phys. 20071;69:426-33.

19. Caloglu M, Ciezki JP, Reddy CA, Angermeier K, Ulchaker J, Chehade N, et al. PSA bounce and biochemical failure after brachytherapy for prostate cancer: a study of 820 patients with a minimum of 3 years of follow-up. Int J Radiat Oncol Biol Phys. 2011;80:735-41.

20. Nag S, Bice W, DeWyngaert K, Prestidge B, Stock R, Yu Y. The American Brachytherapy Society recommendations for permanent prostate brachytherapy postimplant dosimetric analysis. Int J Radiat Oncol Biol Phys. 2000;46:221-30.

21. Stock RG, Stone NN. Importance of post-implant dosimetry in permanent prostate brachytherapy. Eur Urol. 2002:41:434-9.

22. Ho AY, Burri RJ, Cesaretti JA, Stone NN, Stock RG. Radiation dose predicts for biochemical control in intermediaterisk prostate cancer patients treated with low-dose-rate brachytherapy. Int J Radiat Oncol Biol Phys. 2009;75:16-22.

23. Henry AM, Al-Qaisieh B, Gould K, Bownes P, Smith J, Carey $B$, et al. Outcomes following iodine-125 monotherapy for localized prostate cancer: the results of leeds 10-year singlecenter brachytherapy experience. Int J Radiat Oncol Biol Phys. 2010;76:50-6.

24. Ash D, Al-Qaisieh B, Bottomley D, Carey B, Joseph J. The correlation between $\mathrm{D} 90$ and outcome for $\mathrm{I}-125$ seed implant monotherapy for localised prostate cancer. Radiother Oncol. 2006;79:185-9.

25. Stone NN, Hong S, Lo YC, Howard V, Stock RG. Comparison of intraoperative dosimetric implant representation with postimplant dosimetry in patients receiving prostate brachytherapy. Brachytherapy. 2003;2:17-25. 
26. Nag S, Shi P, Liu B, Gupta N, Bahnson RR, Wang JZ Comparison of real-time intraoperative ultrasound-based dosimetry with postoperative computed tomography-based dosimetry for prostate brachytherapy. Int J Radiat Oncol Biol Phys. 2008;70:311-7.

27. Zelefsky MJ, Kuban DA, Levy LB, Potters L, Beyer DC, Blasko JC, et al. Multi-institutional analysis of long-term outcome for stages T1-T2 prostate cancer treated with permanent seed implantation. Int J Radiat Oncol Biol Phys. 2007;67:327-33.
28. Polo A, Salembier C, Venselaar J, Hoskin P; PROBATE group of the GEC ESTRO. Review of intraoperative imaging and planning techniques in permanent seed prostate brachytherapy. Radiother Oncol. 2010;94:12-23.

Correspondence address: Pedro Mocho Galego, MD Department: Section of Urologia São José Hospital, CHLC, Lisboa, Portugal Av. Defensores de Chaves, $24 / 2^{\circ}$ Andar, 1000-117, Lisboa, Portugal Telephone: + 35193 400-1105 E-mail:pamgalego@gmail.com 